\title{
Economic and social convergence in Colombia
}

\author{
Vicente Royuela \\ AQR-IREA Research Group. Universitat de Barcelona \\ Avda Diagonal, 690. 08034 Barcelona (SPAIN) \\ Email.vroyuela@ub.edu \\ Tel. +34934035732 - Fax. +34934021821
}

\begin{abstract}
Gustavo Adolfo García
Universitat Autònoma de Barcelona

Departamento de Economía Aplicada.

Campus de Bellaterra, Edificio B, 08193 Bellaterra, Cerdanyola, Barcelona, (SPAIN)

Email: gustavoadolfo.garcia@uab.cat
\end{abstract}

Tel. +34 935811153 - Fax: +34935812292

\begin{abstract}
GDP has usually been used as a proxy for human well-being. Nevertheless, other social aspects should also be considered, such as life expectancy, infant mortality, educational enrolment and crime issues. This paper investigates economic and social convergence between regions in Colombia, in the period 1975-2005. The main results confirm that there is convergence in Colombia in key social variables, although not in the classic economic variable, GDP per capita. It is also found that spatial autocorrelation reinforces convergence processes through deepening market and social factors, while isolation condemns regions to non-convergence
\end{abstract}

Key words: Latin America; Colombia; economic and social variables; beta and sigma convergence; spatial econometrics 
JEL codes: R11, O47, C23

\section{Convergencia económica y social en Colombia}

\section{Resumen (ESPAÑOL)}

El PIB se usa habitualmente como aproximación al bienestar de las personas. Sin embargo otros aspectos sociales deben ser a su vez considerados, como la esperanza de vida, la mortalidad infantil, la educación y la criminalidad. Este trabajo investiga ña convergencia económica y social en regiones de Colombia en el período 1975-2005. Los principales resultados confirman que existe convergencia en Colombia en variables sociales clave, aunque no en la clásica variable económica, el PIB per capita. También se encuentra que la autocorrelación espacial refuerza los procesos de convergencia a través de la profundización de los factores sociales y de mercado, mientras que el aislamiento condena a las regiones a la no convergencia. 


\section{Economic and social convergence in Colombia}

\section{INTRODUCTION}

GDP is usually used as a proxy for human well-being. Indeed, this is how macroeconomic convergence has been looked at in a wide number of studies at different levels: international (Barro and Sala-i-Martin, 1992 and 1997; Mankiw et al., 1992; Quah, 1996), regional (Lopez-Bazo et al., 1999; Bivand and Brunstad, 2005) and even local (Royuela and Artís, 2006). Improving GDP has been shown to increase life expectancy, provide better access to basic education, etc. As Kenny (2005) argues, "it appears that improving incomes will improve whatever your chosen [quality of life] measure happens to be" (Kenny, 2005, p 1).

Nevertheless, there are other important aspects on the development agenda. The Millennium Development Goals stress eight international development objectives to achieve by the year 2015 . They include reducing extreme poverty and child mortality rates, fighting disease epidemics such as AIDS, and developing a global partnership for development. Moreover, some studies (Easterly, 1999) conclude that many of the improvements in quality of life variables are often not correlated with economic growth rates. Indeed, if some studies fail to find economic convergence at international level Ram (1992) and others find weighted income convergence but unweighted stagnation, mainly due to major changes in large countries such as China and India - others (Kenny, 2005; Crafts, 2000; Ram, 1992) find convergence in well-being indicators.

These days, in terms of policy, the primary debate is concerned with how economic growth is taking place and what the appropriate policies should be. Reports, such as that 
published by the World Bank (2009), argue that growth is "spiky" and that, consequently, any effort to spread economic activity (and, hence, promote convergence) would undermine growth. By contrast, other studies (Garcilazo, 2010) point out that development processes are highly heterogeneous over space and, consequently, policy intervention should mobilize local assets to exploit local synergies. In our view, looking at how economic and social development is taking place in developing countries, such as Colombia, should provide new insights and additional information to further the debate.

The list of social indicators analysed to test convergence is long (including as it does such variables as environmental degradation); however, most studies consider variables related to the Human Development Index, such as life expectancy, infant mortality, educational enrolment and literacy rates (Neumayer, 2003; Goesling and Firebaugh, 2004; Bourguignon and Morrisson, 2002; Becker et al., 2005; Dorius, 2008). Usually their findings lead to mixed conclusions in terms of convergence, depending on the time frame considered and the particular selection of countries and indicators. These papers usually deal with an international context; only a few of them look at a regional level (Giannias et al., 1999; Liargovas and Fotopoulos, 2009; Marchante and Ortega, 2006) and even fewer at a local level (Royuela and Artís, 2006).

This paper seeks to expand the paucity of applied literature conducted in single developing countries by focusing on multidimensional convergence at the regional level in Colombia for the period 1975-2005. Colombia is a developing country with historical social problems related to violence, but it presents significant increases in almost all indicators of social development. Moreover, spatial agglomeration is marked: the three 
main cities account for $41 \%$ of population and $80 \%$ of economic activity. There is a broad body of literature analysing economic convergence in Colombia, but the list of papers focusing on convergence in social indicators is short and the results are ambiguous. Consequently, we believe that this case study represents an additional step in examining how economic and social growth takes place in developing countries. This paper reviews some of this evidence and examines the issue of convergence in quality of life over a number of variables. It seeks to explain the findings that emerge and what these results might mean in policy terms, especially, as regards the definition of a regional policy.

Additionally, many techniques have been adopted for describing convergence in living standards, including $\beta$-convergence, $\sigma$-convergence and kernel density estimates among others. Similarly, as the spatial distribution of these variables matters, particularly at regional level, special attention has been given to the use of spatial statistics and spatial econometrics. This paper seeks to report robust convergence results by resorting to a wide range of available analytical techniques. Given the spatial nature of this case study, we seek to add to the empirical evidence on one specific question posed in the literature: What is the relationship between convergence and spatial autocorrelation?

The results suggest clear convergence paths in four out of the six variables, which we consider as being representative of Sen's $(1973,1987,1993,1997)$ "good life". This evidence is strong enough to affirm that there is a convergence process at regional level in Colombia, despite the fact that this is not shown by variables such as real GDP per capita. The analysis also indicates that spatial autocorrelation reinforces convergence 
processes through deepening market and social factors, while isolation (such as that experienced by the department of Chocó) condemns regions to non-convergence.

This article is structured as follows. The next section presents an overview of recent research on regional income convergence. Section 3 describes the cases studied and the databases used. The empirical evidence is presented in Section 4. Finally, Section 5 concludes and discusses the implications in terms of regional policy.

\section{CONVERGENCE CONCEPTS}

Baumol (1986) stimulated a large number of studies examining the convergence hypothesis, with early followers being Barro (1991) and Barro and Sala-i-Martin (1991 and 1992). These papers use the so-called $\beta$-convergence approach, where the economic growth of a list of economies depends on their initial level. If a significant coefficient of this convergence equation is found, then poor countries grow more than rich countries, and consequently a convergence process exists. In particular, Barro and Sala-i-Martin (1991) suggest the following growth equation:

$$
\left(\frac{1}{T}\right) \log \left(\frac{Y_{t}}{Y_{0}}\right)=c-\frac{\left(1-e^{-\beta t}\right)}{t} \log Y_{0}+u_{t},
$$

where the average growth rate of per capita income depends negatively on its initial level, conditioned on the exogenous growth rate of technology, on the steady state value per effective worker and on the initial level of technology. Parameter $c$ summarises the unobserved parameters, such as the steady state values. The speed of convergence to the steady state, $\beta$, is the rate at which the representative economy approaches its steady 
state growth path, and consequently this procedure of convergence analysis is known as $\beta$-convergence.

A more basic analysis comprises the use of OLS estimation on a cross-section of data. The assumption is that the economies considered in the database belong to a homogeneous system. Of course, it may be the case that this hypothesis does not hold. The solution for this is the use of an additional set of explanatory variables $(\mathrm{X})$ that represent proxies for different steady states in the cross-section regression.

As it is not easy to identify such explanatory variables proxying the steady state of every economy, a frequent empirical alternative is the use of panel data methods. Through the use of fixed effects, the steady state of every economy can be estimated. A simple model might be:

$$
\log \left(\frac{Y_{t}}{Y_{t-1}}\right)=c_{0}+c_{1}(t)-b \log Y_{t-1}+u_{t}
$$

where $c_{0}$ is an unobservable economy-specific effect, and $c_{1}$ is a time specific fixed effect affecting all economies. Nevertheless, panel data estimations also present a number of drawbacks: if most of the variation in the key variables is cross-sectional rather than within regions, fixed effect approaches could give misleading results (Barro, 2000). That is, if the underlying causal factors in the growth process are persistent, the long-run cross-sectional effects will be subsumed into the region fixed effects, which means the explanatory coefficients of the initial level of the endogenous variable are much less informative. Additionally, measurement-error bias is worsened by only using within region variation (Banerjee and Duflo, 2000), so that the bias may be more severe 
than when using simple OLS. Partridge (2005) concludes that fixed effects estimates may produce inaccurate results for measures that mostly vary cross-sectionally. Contrary to fixed effects, random effects and between panel data estimates, will result in results closer to standard OLS when most of the variation is cross-sectional.

Consequently, OLS cross-sectional models capture the way in which persistent crosssectional differences in inequality affect long-run growth rates, which is more relevant to understanding growth disparities, while fixed effects panel techniques capture how time-series changes within a region affect changes in its growth rate over time. Therefore, the two methods are complementary and may reflect different perspectives.

In the panel estimates, both the Hausman and the Breusch-Pagan tests can be used to determine whether to use a fixed or random effects model. Nevertheless, Mairesse (1990) warns that the Hausman test assumes that the model's assumptions hold in the fixed effects model (e.g., no measurement error), and any violations could seriously affect the test results. Additionally, Hsiao and Sun (2000) argue that as the Hausman test has no clear alternative hypothesis, classic sampling theory may not apply. Thus, they recommend the use of simple model selection procedures, such as the AIC statistic, which is much higher in the case of the random effects model. In order to simplify the final results, here, ultimately, we prefer to use OLS cross-section long-run estimates together with fixed effects panel short-run estimates. We, therefore, avoid using random effects panel estimates, as they are potentially non consistent, and the long-run information is basically captured in the OLS estimates. 
A further indicator of convergence involves distributing the variable in two different time periods. The more basic measure, the so-called $\sigma$-convergence (Quah, 1993a), is usually measured by either the standard deviation or the coefficient of variation in these two different time periods. The $\sigma$-convergence enables us to determine whether a variable is becoming increasingly more similar across the economies studied.

As Quah (1993a) explains, $\beta$-convergence is necessary but not sufficient to achieve $\sigma$ convergence and thus $\beta$ and $\sigma$ convergence need to be considered together (Sala-iMartin, 1996). Magrini (2007) points out that the distribution dynamics approach proposed by Quah (1993a and b, 1996a, b and c, and 1997) explicitly contends the $\sigma$ convergence point of view and expands it with the use of stochastic kernels to capture the time evolution of the behaviour of the entire cross-sectional distribution of a variable. We briefly present some concepts needed for our estimation for the distributional approach.

As usual in this kind of analysis all variables are expressed relative to the national average, which allows abstraction from changes in the mean when we look at how the distribution changes. In order to facilitate the comparison, we consider the logarithm of the relative variables. In this way all values can be interpreted as the difference in proportional terms with respect to the national mean.

The kernel density estimate $\hat{f}_{h}$ of a univariate density $f$ based on a random sample $X_{l}$, $X_{2}, \ldots, X_{n}$ of size $n$ is

$$
\hat{f}_{h}(x)=\frac{1}{n h} \sum_{i=1}^{n} K\left(\frac{x-X_{i}}{h}\right)
$$


where $h$ is the kernel bandwidth smoothing parameter, and $K$ is the kernel which is a symmetric probability density function. In order to determine whether there is convergence in our relative variables in logarithmic form, we need to apply Silverman's test to verify if there is uni- or multimodality in the estimated densities, and to see how the dynamics of the entire distribution change between the start and end periods.

For a bivariate random sample $\mathbf{X}_{1}, \mathbf{X}_{2}, \ldots, \mathbf{X}_{\mathrm{n}}$ drawn from a density $f$, the kernel bivariate density estimate is defined by

$$
\hat{f}_{\mathbf{H}}(\mathbf{x})=\frac{1}{n} \sum_{i=1}^{n} K_{\mathbf{H}}\left(\mathbf{x}-\mathbf{X}_{i}\right)
$$

where $\mathbf{x}=\left(x_{1}, x_{2}\right)^{\mathrm{T}}$ and $\mathbf{X}=\left(X_{1} X_{2}\right)^{\mathrm{T}} . K$ is again the kernel function, $\mathbf{H}$ is the bandwidth matrix which is symmetric and positive-definite, and $K_{\mathbf{H}}=|\mathbf{H}|^{-1 / 2} K\left(\mathbf{H}^{-1 / 2} \mathbf{x}\right)[1]$. We also estimated the three-dimensional plot representation of the estimated bivariate density and a contour plot. The main diagonal in these graphs represents persistence, as the elements in the cross-sectional distribution remain where they started. Perfect convergence is found if most of the graph is around the average of the time $t+s$ axis and parallel to the time $t$ axis. Finally, the intra-distribution analysis can be undertaken by searching for the formation of separate modes, a signal of polarization (stratification) in the distribution.

Finally, studies such as those reported by Bernat (1996) and Rey and Montouri (1999) were among the first to include spatial effects in growth regressions, paying special attention to the spatial distribution of the variable. "The problem with aspatial empirical 
analyses that have ignored the influence of spatial location on the process of growth is that they may have produced biased results, and hence misleading conclusions" (Fingleton and Lopez-Bazo, 2006, p. 178). In other words, the basic assumption of independence between observations was usually violated in the analysis of convergence. Rey and Montouri (1999) checked for $\sigma$ - and $\beta$-convergence under spatial heterogeneity and spatial dependence, and found that, because of these spatial behaviours, convergence processes may display complicated transitional dynamics, which have to be taken into account.

Spatial econometrics estimation methods have to be considered, both in the crosssection estimates and in the panel data approach. (Abreu et al. 2005 survey the existing evidence of the empirical facts). In the cross-section approach, several estimation alternatives emerge, including the spatial error model, the spatial lag model, the spatial cross-regressive model, and even the autoregressive and spatial error models. In our paper we consider just two basic models: the spatial error and the spatial lag models. Thus, we do not consider the autoregressive and spatial error models. Even though it may appear convenient to combine the spatial lag and the spatial error dependence, it is difficult to determine which is more relevant, and it is also more difficult to interpret the spatial coefficients:

Spatial error model

$$
\ln \left(\frac{Y_{t+k}}{Y_{t}}\right)=\alpha+\beta \ln \left(Y_{t}\right)+\varepsilon_{t},
$$

where $\varepsilon_{t}=\lambda W \varepsilon_{t}+u_{t}$

Spatial lag model

$$
\ln \left(\frac{Y_{t+k}}{Y_{t}}\right)=\alpha+\beta \ln \left(Y_{t}\right)+\rho W \ln \left(\frac{Y_{t+k}}{Y_{t}}\right)+\varepsilon_{t}
$$


The panel data approach with spatial effects has been developed more recently in Elhorst (2001 and 2003), and recent applications include Arbia and Piras (2005), Arbia, Basile and Piras (2005), Arbia, Elhorst and Piras (2005) and Elhorst (2005).

The distribution dynamics of the spatial dimension of the variables are also relevant. We consider here just one statistic of spatial association between similar values, Moran's I [2] When inspecting the significance level of the statistic, we considered both the bootstrap approach, assumed for instance in GeoDa, based on 1,000 permutations to identify the pseudo-significance of a given value, and the p-values that can be derived from the theoretical distribution of the statistics. In order to be restrictive, we chose not to reject the null hypothesis of non significance when one of the two criteria did not support spatial autocorrelation.

When inspecting the dynamics of the distribution of a variable, we assume that both the magnitude and spatial distribution are important. More recently Rey and Janikas (2005) provide a review of methodological approaches with spatial effects of regional growth processes, and propose several research questions, such as "What is the relationship between convergence, inequality and spatial autocorrelation?” (Rey and Janikas, 2005, p. 168).

As our main aim is to analyse convergence and growth patterns in socio-economic variables, we inspect all possible techniques and sources of convergence to obtain robust results (see Magrini, 2007, for an excellent survey): we examine the distribution of the variables over time, analysing sigma convergence and the spatial behaviour of the 
variable. These statistics are complemented with stochastic kernels and the corresponding contour plot [3]. Finally, when computing $\beta$-convergence we use robust spatial econometric techniques using a simple contact $\mathrm{W}$ matrix.

\section{CONTINENTAL REGIONS OF COLOMBIA: BACKGROUND}

Colombia is a medium-income nation with some 44 million inhabitants and a land area of about $1,200,000 \mathrm{~km}^{2}$. It is a country located in northwestern South America that shares borders with several countries and has access from the north to the Caribbean Sea and from the west to the Pacific Ocean. It is made up of thirty-two departments and Bogotá, the Capital District [4]. Departments are country subdivisions similar to US states and are granted a certain degree of autonomy.

Until the late twentieth century, Colombia had had moderate but stable economic growth accompanied by high levels of poverty, inequality and violence. The annual growth rate of GDP between 1990 and 2008 was around 3.4\%, but the proportion of people living below the poverty line ( $\$ 1.25$ PPP per day) was $16 \%$ and the Gini coefficient was $58 \%$. The intentional homicide rate was 33.4 per 100,000 population in 2010 and conflict and insecurity induced an internally displaced population of more than 3 million persons in 2008. For an international comparison of these main economic and social indicators see Table 1.

Colombia is a country of regions, most of them having idiosyncratic characteristics in geographical, economic and socio-cultural terms (see the map in Figure 1). The geographical characteristics have clearly influenced the other traits. Most urban centres 
are located in the highlands of the Andes Mountains or cordilleras. There are three main cities located in the cordilleras: Bogotá (the country's capital), Medellín (capital of Antioquia) and Cali (capital of Valle). These three cities concentrate $41 \%$ of the total population and about $80 \%$ of economic activity (Galvis, 2001). In contrast, those regions located on the periphery or in hard-to-access geographical areas are the poorest. They include Chocó, the Amazonía, Nariño and La Guajira. Other poor regions are located close to maritime borders, such as Bolivar, Magdalena, Sucre and Cauca.

\section{- Figure 1 -}

The discovery of large mineral deposits in the 1980s and 90s increased the contribution of several departments to the national product. This is the case of the departments of Arauca and Casanare, which have the largest oil fields in the country (Caño Limón and Cusiana-Cupiagua respectively), and La Guajira, home to the Cerrejon mines, the largest opencast coal mine in Latin America, and the salt mines in Manaure, the biggest open pan salt mines in the world.

Regional inequality and the geographical concentration of poverty in the coastal departments are two of the main characteristics of Colombia, and several authors (such as Meisel, 2007) have stressed that economic and social disparities have deepened in the last 15 years. Consequently, the study of these disparities and the search for a potential convergence/divergence process are important issues for researchers to undertake.

- Table 1 - 
Results concerning economic convergence in Colombia vary by the period of analysis and the technique applied. Cárdenas (1993) and Cárdenas et al. (1993 and 1995) reported strong convergence in the period 1950-1990. However, Meisel (1993), with a similar GDP database and period of analysis, found that although there was convergence in the period 1950-1960, this was not the case for the period 1960-1990. Meisel's (1993) findings suggest that Cárdenas's results may have been biased and misinterpreted due, among other reasons, to errors in the database. Birchenall and Murcia (1997) failed to find any convergence process when using stochastic kernel estimates in per capita income at departmental level, and stressed the impact of the mobilization of poor regions following rapid growth in the mining industry (oil fields). Rocha and Vivas (1998) applied an alternative methodology (exchangeability priors) and showed that Colombia underwent a process of regional polarization in the period 1980-1994, that there are different regional steady states, and consequently that the hypothesis of economic convergence is not fulfilled.

Bonet and Meisel (1999) also used the GDP measure from the Banking Superintendence of Colombia and analysed regional convergence by applying a wide range of techniques for two broad periods, 1926-1960 and 1960-1995. Their results show that in the first period there was economic convergence, while in the second there was a process of polarization. Sánchez and Núñez (2000) and Galvis and Meisel (2000) analysed absolute and conditional $\beta$-convergence using GDP at municipal level, and found that there was conditional convergence between the 70s and 90s.

Using data from the National Department of Statistics (DANE), the papers by Acevedo (2003), Barón and Meisel (2003) and Barón (2003) found convergence during the 
eighties but not during the nineties. Barón's paper (2003), using spatial dependence techniques (Moran's I and Geary's C), found that the departmental per capita GDP did not show any pattern, indicating the random geographical distribution of wealth and poverty in Colombia.

In 2004 and 2006 the Centro de Estudios Ganaderos (CEGA) produced new estimates for GDP and income at departmental level in Colombia for the period 1975-2000. Gómez (2006) and Bonet and Meisel (2006 and 2008) found conditional convergence and decreasing sigma convergence, but also a process of polarization in income between Bogotá and the rest of the nation. Branisa and Cardozo (2009a) and Franco and Raymond (2009) observed slow convergence in disposable household income, but no convergence in GDP and convergence clubs, respectively.

Few studies consider convergence in non-economic social indicators. Meisel and Vega (2007) showed that the average height of Colombians increased in every decade throughout the 20th century, and there is also convergence in this indicator between men and women, a proxy of social development. Ardila (2004) looked at the percentage of people with unsatisfied basic needs and the index of living conditions, and found geographical persistence in the variables.

Aguirre (2005), Martínez (2006) and Branisa and Cardoso (2009b) used health and education indicators to analyse social convergence between 1973 and 2005, using DANE data. The first two papers, by estimating $\beta$-convergence and univariate kernels, found that while the infant mortality rate converged, education indicators (the illiteracy rate and the basic education variable) did not. Similarly, Aguirre (2005) also found 
convergence in life expectancy at birth. Contrary to these results, Branisa and Cardoso (2009b) found convergence in the education indicators but not in those of health.

Overall, there are conflicting results in the literature for both economic and social variables, and consequently additional work would be helpful in analysing convergence from a multidimensional point of view.

\section{DATA SOURCES}

When analyzing economic and social indicators a key issue is the selection of variables to be considered in the study. Sen $(1973,1987,1993,1997)$ argues that a 'good life' is composed of four key elements: material well-being, health and survival, education and personal development and social inclusion/participation. In order to evaluate these elements of well-being or standard of living, Sen (1987) claims that the selection of indicators should consider two issues: the actual outcome of peoples' decisions, and their capabilities (the opportunities they have). Researchers have used variables such as GDP, per capita income and unemployment to measure capabilities and life expectancy at birth, infant mortality rates, literacy rates and educational enrolment, telephone, television and Internet availability to evaluate actual outcomes (Hobijn and Franses, 2001; Neumayer, 2003; Dowrick et al., 2003; Kenny, 2005).

In this paper we analyse the following variables: real GDP per capita, real disposable household income, life expectancy at birth, infant survival rate, literacy rate and murder rate. The first two are the most commonly used economic variables. Note that we do not include the variable of unemployment, which clearly has a marked influence on wellbeing and represents an important social aspect of life, because of data availability [5]. 
In terms of regional convergence analysis we assume that this variable plays a key role since, as Elhorst (2003b) claims, wide unemployment differentials imply inefficiency in the economy as a whole and reduce economic growth and development. However, based on an examination of the only available information (for seven metropolitan areas of Colombia), the correlation between unemployment and per capita GDP and disposable income was significantly high [6]. Thus, the main economic outcomes of unemployment differences would appear to be assumed by the economic variables. By contrast, the social implications of unemployment are examined here by analysing other social variables.

As regards social indicators, we include variables related to health, education and, a key aspect of life in Colombia, crime. In our view, these variables when considered together capture fundamental aspects of the country's standard of living and, consequently, we believe we capture the main aspects of Sen's 'good life'.

The evidence from previous studies has shown that the results obtained depend on the database used. Next, we describe the sources and implementation concerns related to each variable. The entire database with a fuller description of building procedures is freely available and can be accessed at the website of the authors. As far as GDP is concerned, we have chosen to merge different data sources: the National Department of Statistics (DANE) and the Centro de Estudios Ganaderos (CEGA). The former provides GDP data for the period 1990 to 2005 for all 33 departments, while the latter provides data on GDP and income from 1975 to 2000 but only includes 23 departments: the capital district of Bogotá and the nine "New Departments" grouped into a single observation (a total of 25 departments). As our primary interest is analysing the spatial 
distribution of Colombian development, we omit the islands of San Andrés and Providence from the final database, and consequently the database comprises 28 spatial units. In the case of the income variable, DANE does not provide any information and so we use only the CEGA data. Here, only 24 spatial units are considered as the Amazonic departments are not included.

As regards the other social indicators, the main source of data at department level is DANE. The literacy rate was taken from census details provided by DANE in 1973, 1985, 1993 and 2005. To determine the variable for the 28 departments, the micro data are drawn from the IPUMS [7] databases which present the variable for the illiteracy rate in positive terms (i.e., the proportion of individuals who can read). Both health variables (life expectancy at birth and infant survival rate) were considered for the periods 1985-1990, 1990-1995, 1995-2000 and 2000-2005. Finally, the crime variable (non-murder rate) is computed yearly for the period 1990-2005. All variables are defined positively (i.e., the higher, the better). Although the results of convergence analysis may change according to whether a variable or its complement is used (Micklewright and Stewart, 1999), the positive definition is preferred and here we adhere to Kenny's (2005) arguments: measurements of convergence toward zero are more sensitive to very small changes close to zero than very large changes further from zero. Besides, he claims that convergence towards a positive value is standard in the literature.

As we use census for certain variables, it implies working with growth rates between $t$ and $t+10$ in the panel data approach. In order to be able to make reasonable comparisons, we work with this time window even when we have annual data. 
Moreover, by taking this approach we are able to follow the line adopted by existing literature (Partridge, 2005).

In Figure 2 we show the spatial distribution of the variables at department level in 2005. Overall, it can be seen that in economic terms the departments of Chocó, Sucre and Córdoba have the lowest levels of income per-capita, while Bogotá and Antioquia have the highest levels. As regards social variables, the pattern does not change: Chocó is the department with the lowest levels of literacy, life expectancy at birth and infant survival. The geographic location and, to a greater extent, government neglect have conditioned the social and economic under-development of Chocó. In the case of the crime variable, the departments in which armed groups outside the law operate and in which the illegal drug trade is prevalent are the ones with the highest levels of violent deaths. The Guerrilla operates above all in the departments of Putumayo, Caquetá, Meta and Arauca, while the Carteles have considerable presence in the departments of Valle and Risaralda.

\section{- Figure 2-}

Of course, all the variables considered are related. GDP per capita is highly correlated with real per capita household available income (the linear correlation for the last available year is 0.88 ), but it presents a lower correlation with the other variables (the highest being 0.34 with infant survival rate). Social variables display higher correlations with income (but recall that income involves a restricted sample from which the new departments are excluded) and between each other, e.g., the literacy rate is correlated with infant survival rate $(0.50)$, both health variables are highly correlated $(0.70)$ and the non homicide rate is correlated with life expectancy at birth (0.51). Consequently, these 
figures demonstrate that development is a multidimensional concept and that both economic and social variables are worthy of attention.

\section{RESULTS}

Table 2 displays the key statistics of all the variables, while Tables 3 and 4 show, respectively, the details of model estimates of $\beta$-convergence for cross-section (equation 1) and panel data (equation 2), as well as when using spatial error (equation 5) and the spatial lag (equation 6) specifications. For each variable, we also show the univariate kernel density estimate and contour plot of the initial and final years considered (see Figures $3 a$ to $8 b)$.

- Table 2 -

- Table 3 -

- Table 4 -

- Figures of Univariate kernel density and contour plot -

\section{Economic Convergence}

The real GDP per capita in Colombia over the 31-year period (1975-2005) grew at an average annual rate of $1.7 \%$. There were important periods of expansion (1986-1987, 1994-1996) as well as recession (end of the nineties). In the case of $\sigma$-convergence, Table 2 shows that from 1975 to 1985 the situation remained fairly stable with low levels of dispersion. 1986 saw the initiation of a massive increase in the coefficient of variation $(\mathrm{CV})$, with maximum values being recorded in 1999. Consequently, economic expansion was accompanied by an increase in dispersion. After that year, there was a significant decrease in the CV, although in 2000 it was still above its initial 1975 level. 
Thus, the sigma convergence path indicates that we cannot, in fact, talk about convergence.

The stochastic kernels show no significant changes in distribution between 1975 and 2005. Only two regions, Casanare and La Guajira, are located above the 45-degree diagonal, indicative of a process of mobility in these regions due to the development in mining that has occurred since the late eighties. The rest of the distribution remains some distance from any convergence path.

Spatial autocorrelation is barely significant throughout most of the period analysed. If the level of significance is set at $10 \%$, only 9 out of the 31 years considered are nonsignificant, and when the significance level is set at 5\%, only the period 1990-1997 displays significant Moran's I statistics. Interestingly, spatial autocorrelation evolves over time in parallel with the CV: low values at the beginning, a massive increase after 1986 through to 1997 , followed by a sharp decrease. Thus, real GDP per capita dispersion and spatial dependence display a positive covariance over time. The evidence found for Colombian GDP is basically the same as that reported in Rey and Montouri (1999) and Rey and Janikas (2005) for the USA: a positive relationship between $\sigma$ convergence and spatial dependence [8]. Thus, low levels of dispersion seem to imply low spatial dependence, while subsequent convergence leads to low levels of spatial dependence. In any case, the results show that non-convergence occurs with nonsignificant spatial autocorrelation, which contrasts with the situation in the USA as reported by Rey and Montouri. 
Finally, Tables 3 and 4 show the $\beta$-convergence estimates. These tables display both the long-run OLS cross-section analysis and the short-run fixed effects panel estimates. In the long-run cross-section estimates we found non-significant negative parameters and also a non-significant influence of spatial dependence. Panel data estimates use annualized growth rates of ten-year periods as dependent variables. Although not reported, the within dispersion greatly exceeds the between dispersion, which is mainly controlled using time series fixed effects, and consequently most of the variation of the endogenous variable in the panel relates to the time series dimension and leads us, following Partridge (2005) - see above - to consider short-run results. In this respect, the fixed effects panel estimates suggest a high, significant speed of convergence $(6.5 \%$ in the preferred spatial lag model) which implies that every region converges to its own steady state in just 7.3 years.

As a whole, therefore, analysis of sigma convergence and the kernel estimates was not strongly supportive of convergence for the whole period. The same results are obtained in the long-run $\beta$-convergence analysis, but not in the fixed effects panel data estimates, and this supports the idea of convergence. The previous literature points to the fact that once mining departments are excluded convergence disappears (Birchenall and Murcia, 1997). This evidence is supported here with kernel analysis.

Nevertheless, if the correlation coefficient between GDP growth and the log of initial GDP is -0.26 , when we exclude Amazonía, Arauca, Casanare, La Guajira, and Putumayo (the mining departments which accounted for $19 \%$ of Colombian GDP in 1975 and $22 \%$ in 2005), the coefficient falls to -0.04 . Thus, it cannot be argued that the convergence can be explained in terms of the neoclassical growth theory, based on 
mobility factors and decreasing marginal returns, but rather it reflects changes in the steady state conditions of a number of departments.

Next we analyse real departmental per capita household income. One of the limitations in the debate on regional convergence in Colombia is that departmental per capita household income was not directly measured until CEGA began to estimate this series in 2006. The advantage of income over GDP is that the latter is a measure of the production generated by individuals within a department, while the former is an estimate of the income received by individuals residing in that region. In other words, the data on GDP is not a good reflection of the level of prosperity in the regions (Bonet and Meisel, 2006) because it reproduces the portion of production generated and captured by individuals, and so it is not affected by the sectoral composition of production. A typical example of the differences between GDP and income is the production of energy. This sector presents high apparent productivity (GDP per worker), but its corresponding personal income is usually quite low. The results above show that sectoral composition is an important aspect to take into consideration in Colombian departments.

However, there is a trade-off in the use of personal income in Colombia. The available series, computed by CEGA, covers 1975 to 2000 and does not include certain departments (Arauca, Casanare, Putumayo and Amazonía, the ones with oil fields). Consequently, the analysis is partial and excludes the influence of mining activities.

First, we analyse the evolution in dispersion. Inversely to the situation described for real GDP, there was a fall in the CV for income from 0.46 in 1975 to 0.33 in 2000 [9]. This 
decrease was particularly marked after 1987. The kernel estimates and contour plot enable us to confirm the convergence process at the tails of the distribution (at its highest and lowest points). The poorest region in 1975 (Chocó, 39\% of the national average) was not so poor in 2000 (51\%), and the richest in 1975 (Bogotá, 275\% of the national average) was not so rich in 2000 (206\%). Additionally, there was a large increase in density around the distribution's average.

Again, inversely to the situation described for real GDP, the spatial autocorrelation in real per capita income is never significant, despite a slight increase in Moran's I statistics in 1992 and 2000. Additionally, we did not find the same positive relationship between dispersion (CV) and spatial autocorrelation (Moran's I statistic) that was reported in GDP. On the contrary, there is a negative correlation between both statistics of -0.33 . Consequently, it would seem that the positive relationship between the $\mathrm{CV}$ and Moran's I in Colombia's economic variables is due only to the emergence of a positive cluster of small departments based on oil fields in 1986. What the rest of the country experiences is a total absence of spatial autocorrelation.

The $\beta$-convergence analysis confirms the above analysis: there is a significant negative parameter for all regressions, with a speed of convergence in the long run equal to $1.44 \%$ (OLS estimates) and in the short run equal to $7.27 \%$ (fixed effects panel estimates), when all departments converge to their own steady state. Spatial estimates are not particularly preferred over the others. Unlike the GDP estimates, the estimates are now better adjusted, and consequently, despite the fact that the estimates do not differ so much different, they are more reliable and, therefore, statistically significant. 
The evidence as a whole is supportive of the idea of convergence: the CV decreases, particularly after 1985; the kernel estimates show that convergence occurs above all at the tails of the distribution; and, finally, the estimations of $\beta$-convergence are significant. And, interestingly, all this occurs in the total absence of spatial autocorrelation.

\section{Social Convergence}

We start our analysis of social variables by examining education. The literacy rate (the percentage of literate population over 15) is considered here. In general terms it experiences a positive evolution: the proportion of people who can read and write has grown steadily from $78.4 \%$ in 1975 to $89.2 \%$ in 2005 . As regards sigma convergence, the $\mathrm{CV}$ decreased from 0.11 to 0.06 . The kernel density estimate clearly shows the large decrease in the dispersion. However, the presence of several modes below the average suggests that several departments continue to lag behind the rest of the country [10]. There is also a fairly flat contour plot with few exceptions (mainly La Guajira, whose position worsens in 2005).

Parallel to this there is an increasing evolution of the global spatial autocorrelation measurement, which always displays a positive sign but is only significant in 1985 and 2005. Although not reported here, the Moran scatterplot is only affected by a single region, Chocó, a naturally isolated department on the Pacific coast. Analysing the evolution of dispersion and spatial autocorrelation and concentration over time, we note that the CV is negatively correlated with Moran's I (the correlation between these two

measurements being -0.63). Consequently, in literacy rate, as the spatial relationship 
between departments increases, relative differences decrease. In other words, regional convergence is associated with significant spatial autocorrelation.

Finally, the results for $\beta$-convergence indicate that there is strong convergence process, both because of the significant parameters in the regressions and because of the high adjustment levels of the estimates: with just one explanatory variable (the initial level of the endogenous variable) it is possible to account for more than $60 \%$ of the variation in growth of the literacy rate. In this case, the spatial error model is preferred over the OLS and the spatial lag models (according to the robust LM tests). This means that there are non-observed aspects in the growth rate following spatial patterns. In these situations conditional models merit particular attention. In this estimation the implicit yearly speed of convergence is up to $1.8 \%$. Panel data models show higher estimates of the speed of convergence: the results show a higher speed of convergence in the conditional models displayed in panel fixed effect estimates. Once individual effects are controlled for, nonspatial estimates are preferred and display a short-run speed of convergence of $4.7 \%$ towards every region's steady state.

Overall, the literacy rate shows a strong convergence process, which is combined with the increasing importance of spatial dependence and concentration between regions.

We continue our analysis of social convergence by considering life expectancy at birth. The results show a large increase in this variable over the 30-year period. If in 1975 life expectancy at birth was 66.3 , in 2005 it had risen to 71.1 . During this period the CV underwent a significant fall: from $5.8 \%$ in 1975 to $3.5 \%$ in 2005 . The kernel estimates show a marked decrease in the dispersion of the variable and a contour plot moving 
away from the diagonal of the box, approaching the horizontal line. This evolution was parallel to a slight decrease in the measure of spatial autocorrelation, which, in any case, is always positive and highly significant. Here, again, the evolution presented by Chocó accounts for the decrease in the evolution of Moran's I statistic.

The $\beta$-convergence estimates present significant parameters together with high levels of adjustment in all regressions. Despite finding strong spatial autocorrelation, non-spatial estimates are preferred over these spatial specifications. In all cases, the speed of convergence is significant but quite low $(1.39 \%$ in the OLS long-run estimates and $2.53 \%$ in the non spatial fixed effects panel estimates, as the robust tests did not reject the null hypothesis). In this case, the speed of convergence from panel and OLS estimates is relatively similar (much more so than in previous situations). Thus, the convergence process may be seen as a national phenomenon, based in all probability on the country's overall economic growth.

Next we look at the infant survival rate, i.e., the positive variable of the more commonly defined infant mortality rate. It is usually assumed to reflect the health condition of the population more directly than life expectancy at birth, due to the influence of the availability of health facilities. Parallel to the increase in life expectancy at birth observed above, the infant survival rate increased from $95.2 \%$ surviving infants under 5 years old in the period $1985-1990$ to $96.4 \%$ in $2000-2005$.

As with the other social variables, there was a small decrease in dispersion, with the CV shifting from $1.51 \%$ to $1.46 \%$ in the period under study. The kernel estimates show a mode represented by the department of Chocó (some way below that of the other 
departments), which is strongly persistent over time [11]. Apart from this, lying close to the average we initially find some poorly placed departments that subsequently undergo a positive convergence process, while other departments that were initially above average move towards the maximum.

These movements in the dispersion of the variable have been observed together with a fall in Moran's I statistic, from 0.18 in 1985-1990 to 0.08 in 2000-2005 (the correlation over time is close to 0.90 ). Moran's I is no longer significant at the $10 \%$ level in the period 1995-2000. Again as a result of the influence of Chocó, the eventual Moran's statistic is low and decreasing (as Chocó's neighbours improved their performance as regards this indicator) [12].

The $\beta$-convergence estimates are insignificant for all cross-section estimates, but the preferred spatial lag model, which displays a positive and significant parameter for the spatial lag. The panel data models present significant parameters [13], with the spatial lag model being the preferred specification. Here, the negative parameter of the spatial lag model is highly affected by the department of Chocó, as analysed above.

Overall, the infant survival rate presents a modest decline in its $\sigma$-convergence statistic. The main changes in the distribution occur around the average. The department of Chocó has a significant influence on the overall spatial statistics and even on the spatial estimates. Having examined the spatial fixed effects, and taking the particular characteristics of this department into account, we found a modest speed of convergence (1.74\% in the spatial lag panel model) - which is in line with the changes in the CV, and a significant parameter for the spatial lag of the growth rate. 
Finally we analyse crime. Again, this variable is analysed in positive terms by using the non-murder rate, which considers the total number of people out of 10,000 inhabitants who are not killed. The murder rate underwent a significant decline between 1991 (8.2 murders per 10,000 inhabitants) and 1997 (5.7). However, it rebounded until 2002 (7.3) before falling until 2005 (4.1). The CV for the non-murder rate underwent a significant decline during the period considered: it was close to $0.04 \%$ in 1991, while by 2005 it had fallen to $0.025 \%$.

The kernel estimates show a much richer picture of changes in distribution. Firstly, we observe a significant mode below the average in 1990. By 2005 this mode has completely disappeared [14], while the contour plot shows how the department of Antioquia underwent a dramatic change towards the average of this distribution. Contrary to this, a large part of the distribution below the average did not follow this convergence process (in particular, Arauca and Caquetá, which moved from $9^{\text {th }}$ and $10^{\text {th }}$ position in the crime ranking to $1^{\text {st }}$ and $2^{\text {nd }}$ respectively). In these departments, together with Putumayo and others, there is a significant presence of illegal military groups (guerrilla and paramilitary) and war has been a constant presence for decades.

The strong stance taken against these groups by President Uribe at the beginning of the twenty-first century may have led to an increase in crime. Similarly, Antioquia has been marked by the presence of groups operating outside the law, including drug cartels and urban militia, which led to outbreaks of violence in the nineties, above all in Medellin (its capital). This situation has declined dramatically since 2000, reinforcing the convergence path for this variable. 
The spatial autocorrelation measured by Moran's I statistic was simply non-existent in all of the periods under analysis, and in addition there is no overall trend. In the case of this variable, Moran's I statistic displays a small negative correlation over time with the CV (the higher the spatial autocorrelation, the lower the CV).

$\beta$-convergence is significant in all estimates and at high rates. As expected, spatial specifications are not important in the cross-section models, where the speed of convergence is $3.35 \%$ (OLS with no spatial effects). Panel fixed effects estimates show, as usual, a higher speed of convergence ( $4.64 \%$ in the preferred spatial lag model). As expected, these estimates are affected by the dramatic decline in violent episodes recorded in Antioquia. If the correlation coefficient between the growth rate and the log of the initial non-murder rate is -0.78 , this statistic collapses to -0.16 when Antioquia is excluded. Consequently, any convergence process in crime is reinforced by the significant decrease in violent episodes in Antioquia.

\section{CONCLUSIONS}

In this paper we have analysed convergence processes in Colombia, considering not only economic variables but also social indicators of education, health and crime. We have examined sigma convergence, the distribution dynamics of the variables and beta convergence, both in cross-section and panel data specifications. We have also considered the spatial distribution of the variables, through an inspection of spatial autocorrelation statistics, and through the use of spatial econometrics techniques for estimating beta convergence. 
In this analysis, we have found diverging results for GDP per capita (non convergence) and real household disposable income (convergence). Here, our interpretation is that transfers (either public or private, for instance, through regional remittances) may have a key role to play. Thus, even if rich regions remain rich in production terms (GDP) or if several regions become rich because of exogenous factors (the case of the mining departments), new income is more equally distributed over time, which ultimately favours convergence.

The convergence process has also been observed in education (literacy rate) and in the health variables (particularly life expectancy at birth): decreasing $\mathrm{CV}$, significant changes in the kernel estimates towards the average and significant parameters of beta convergence. By contrast, the infant survival rate presents conflicting results, affected above all by the individual results of the department of Chocó. Finally, the convergence process found in crime is strongly influenced by the evolution presented by Antioquia, albeit that this is counterbalanced by the negative evolution of several departments controlled in part by guerrilla and paramilitary groups.

Overall, there seems to be robust evidence of convergence having taken place in Colombia over the last 30 years, in both its economic and social variables. These results are in line with Kenny (2005): convergence in quality of life indicators can be achieved even in the absence of sustained economic growth and convergence. Thus, GDP is only one among a number of factors that determine well-being.

The analysis of spatial trends at the regional scale leads us to consider one of the main questions raised by this paper - the joint analysis of the spatial distribution of the 
variables and the convergence processes. We found considerable diversity in our results; however, overall there is weak evidence of a link between regional convergence and spatial autocorrelation, as a decreasing $\mathrm{CV}$ is accompanied by increases (significant or otherwise) in Moran's I global measure of spatial autocorrelation. When convergence and non-significant spatial correlation were observed, it was mostly a result of the behaviour of certain departments. A clear case in point is that of the department of Chocó, lying on the Pacific coast, but which is separated from the rest of the country by a natural barrier of thick rain forest, making it an 18-hour drive to Medellín, the closest big capital, only $136 \mathrm{~km}$ away. Its isolation is a key factor in accounting for low levels of GDP, income, literacy and infant survival rates, despite the fact that it is surrounded by departments with high levels in all these variables. In these indicators Chocó presents a significant low-high cluster.

These results would seem to indicate that if we are to find evidence in support of the neoclassical growth theory of convergence, based on labour mobility and decreasing marginal returns linked also to capital mobility, some kind of spatial link has to be found between regions. This is in line with previous literature (Aroca and Bosch, 2000, Rey and Montouri, 1999, and Rey and Janikas, 2005), as convergence processes are developed in statistically significant spatial autocorrelation scenarios. In any case, we recognise that more robust evidence is needed here, which might be obtained by analysing a number of variables for a wider sample of countries.

Finally, we consider what our results might mean in policy terms and, particularly, for defining a regional policy. Indeed, recent years have seen the publication of a series of highly influential reports on regional development policy (World Bank, 2009, European 
Commission, 2009, OECD, 2009 a and b and Corporación Andina de Fomento, 2010). Barca et al. (2011) consider such reports as illustrating two alternative policy trends: the space-neutral and the place-based approaches. The differences between them lie, they claim, in relation to the question of "whether the territorial systems in evidence today are the result of a unique first-best solution to efficiency and space or rather of path dependency, sunk costs and institutional issues" (Barca et al., 2011, p. 13). Ultimately, the space-neutral policies supported by the World Bank's World Development Report advocate the advantages associated with agglomeration effects, as any attempt to spread economic activity will undermine growth and prosperity. By contrast, the place-based approach assumes that all regions display growth and development potential, and that development processes are and have been highly heterogeneous (Garcilazo et al. 2010). Consequently, the role of development intervention is to mobilize regional assets to exploit local synergies. Placed-based policies assume the importance of institutions and their interaction with local forces, within the local context. In this line, its advocates argue that urban expansion is the only realistic option in the developing world for growth by overcoming institutional underdevelopment.

Our findings for the Colombian case are set within a national context of economic and urban growth over a 30-year period. This overall trend has clearly helped improve the social indicators of education and health, as, together with technological improvements in the provision of health and education services, providing social services to urban residents is easier than providing them to rural populations (Kenny, 2005). And this result has been recorded with no convergence in real GDP per capita. As such the Colombian case would seem to be an example of development in a country in the process of constructing its institutions. The role of drug cartels, urban militia and the 
guerrilla forces controlling large parts of the country cast doubts of a strong institutional nature throughout the period considered. Thus, the result has been a non convergence process in production terms, and a polarisation of the country's main cities, which contrasts with considerable improvements in the people's well-being.

Major redistribution policies affecting the country's health and education facilities, together with the expansion of its transport infrastructure, may have contributed to balance regional social growth. This seems to imply that there is still considerable scope for government intervention, especially as regards the strengthening of regional policies, for example, extending investments to rural areas [15]. In this line, beta convergence panel data estimates were in many cases higher than the cross-section estimates. Following Islam (1995), a higher beta convergence for the panel estimates, despite expectations, calls for greater policy activism - the main reason being that improvements in each individual region (each steady state) will also lead to higher transitional growth rates (higher speed of convergence).

In our view, a country such as Colombia, characterised by the current development of its institutions, has to continue with the marked economic polarisation in its production while promoting investment in social areas such as education and health throughout the state, as this will subsequently foster the growth of strong local institutions. This recipe may well be controversial, but the question regarding the relationship in the evolution between social and economic variables at the regional level in developing countries certainly deserves the attention of future studies. 
Acknowledgments: Vicente Royuela acknowledges the support of Ministerio de Ciencia e Innovación (ECO2010-16006). Gustavo García acknowledges the support of AGAUR (FI-DGR 2010), and of Ministerio de Ciencia e Innovación (ECO201020718).

Notes

1. For both univariate and bivariate kernel density estimations we use the Gaussian density function. To select the bandwidth of both univariate and bivariate kernel density estimations we use the plug-in methodology proposed by Sheather and Jones (1991).

2. We did consider other complementary alternatives, Geary's C, and Getis and Ord's $\mathrm{G}$, which reported similar results.

3. Given the spatial nature of the analysis, we have considered the possibility of spatial dependence when computing the kernel densities. Consequently, following Getis (1995), we performed a spatial filter and subsequently computed the kernel densities. After inspecting the results of filtered and raw data, we preferred to include the latter outcomes for the following reasons: the results are not substantially different from the unfilterered data and, consequently, presenting one of the two alternative options is enough; spatial dependence is not always important and it could lead to additional confusion if we present alternative methods for all variables; it is not clear what kind of spatial dependence underlies the process, be it one of nuisance or substance, and consequently it is not clear if removing economic and social dependence would lead to our losing important information. 
4. Colombia is divided administratively into departments, districts and municipalities. Before the Constitution of 1991, there were also intendencias and comisarías. The intendencias and comisarias are the "New Departments", and the departments that existed before 1991 are known as the old departments. The "New Departments" include Arauca (Ara), Casanare (Cas), Putumayo (Put), the islands of San Andrés and Providencia, and the group we label as Amazonía Group (GA), formed by the following departments: Amazonas, Guainía, Guaviare, Vichada and Vaupés. The “Old Departments” included Antioquia (Ant), Atlántico (Atl), Bogotá (Bog), Bolívar (Bol), Boyacá (Boy), Caldas (Cal), Caquetá (Caq), Cauca (Cau), Cesar (Ces), Córdoba (Cór), Cundinamarca (Cun), Chocó (Cho), Huila (Hui), La Guajira (La Gua), Magdalena (Mag), Meta (Met), Nariño (Nar), Norte de Santander (Nors), Quindío (Qui), Risaralda (Ris), Santander (San), Sucre (Suc), Tolima (Tol) and Valle (Val).

5. In Colombia this variable is not available at the departmental level, except for a few metropolitan areas. Several papers consider this territorial scope to analyze unemployment convergence (Gamarra, 2006, and Gaviria and Ballesteros, 2010).

6. The correlation between unemployment and GDP per capita is -0.83 for the restricted sample of seven metropolitan areas. Similarly, unemployment correlates significantly with the literacy rate $(-0.84)$, infant mortality rate $(0.58)$, and life expectancy at birth $(-0.45)$.

7. Data are from the Integrated Public Use Microdata Series (Minnesota Population Center, 2010), www.ipums.org.

8. Rey and Montouri (1999) report a correlation coefficient of 0.785 over the period 1929-94 for U.S. regions. 
9. Part of this result is due to the dataset considered. A CV was also computed for real GDP per capita in the narrow dataset of 24 departments, and a decrease in the CV can be observed, particularly after 1999. This implies that convergence in real per capita income could be due to the selection of the dataset.

10. Following Izenman and Sommer (1988) we study graphical displays of the density estimate near each critical window width and we calculate Silverman's test for multimodality (Silverman, 1981 and 1983). We used the routines in Stata proposed by Salgado-Ugarte et al. (1997) to calculate Silverman's test. Results show a rejection of the null hypothesis that the density has a single mode in 2005.

11. Silverman's test for multimodality shows p-values above 0.40 for the null hypothesis that the density has two modes in both periods of time.

12. If Chocó had an infant survival rate equal to the average of the distribution, Moran's I statistic, although decreasing, would have always been significant: 0.44 in 19851990 and 0.37 in 2000-2005.

13. Here, the LM tests signal a preference for the spatial lag model, despite the fact that it has the worst AIC statistic.

14. Silverman's test shows that in 1990 we cannot reject the null hypothesis that the density has two modes, while in 2005 the test shows that the density is unimodal.

15. Along similar lines, Chay and Greenstone (2000) claim that federal interventions during the War on Poverty in the mid-1960s in rural areas of the USA were the main factor responsible for convergence in infant survival rates.

\section{REFERENCES}


Abreu, M., de Groot, H. L. F., Florax, J. G. M. (2005), "Space and Growth: A Survey of Empirical Evidence and Methods", Région et Développement, 21: 13-44

Acevedo, S. (2003), “Convergencia y Crecimiento Económico en Colombia 19802000”, Ecos de Economía, 17: 51-78.

Aguirre, K. (2005), "Convergencia en Indicadores Sociales en Colombia. Una Aproximación desde los Enfoques Tradicionales y no Paramétricos", Desarrollo y Sociedad, 56: 147-176.

Anselin, L. (1988), Spatial Econometrics: Methods and Models, London: Kluwer.

Anselin, L. (1995), "Local Indicators of Spatial Association - LISA”, Geographical Analysis, 27 (2): 93-115.

Anselin, L. and Bera, A. (1998), "Spatial Dependence in Linear Regression Models". In Ullah, A. and Giles, D. (Eds.), Handbook of Applied Economic Statistics, New York: Marcel Dekker.

Anselin, L. and Florax, R.J.G.M. (Eds.) (1995), New Directions in Spatial Econometrics, Berlin: Springer.

Anselin, L. and Rey, S.J. (1991), "Properties of Tests for Spatial Dependence in Linear Regression Models”, Geographical Analysis, 23(2): 112-131.

Anselin, L., Bera, A., Florax, R.J.G.M. and Yoon, M. (1996), "Simple Diagnostic Tests for Spatial Dependence”, Regional Science and Urban Economics, 26(1): 77-104.

Arbia, G., Elhorst, J.P. and Piras, G. (2005), "Serial and Spatial Dependence in the Growth Process of EU Regions", Paper presented at the Workshop on Spatial Econometrics, Kiel Institute for World Economics, Kiel, April 8-9, 2005. 
Arbia, G. and Piras G. (2005), "Convergence in Per-Capita GDP Across European Regions Using Panel Data Models Extended to Spatial Autocorrelation Effects", ISAE Working Paper No. 51, Rome: ISAE.

Arbia, G., Basile, R. and Piras G. (2005), "Using Spatial Panel Data in Modelling Regional Growth and Convergence”, ISAE Working Paper No. 55, Rome: ISAE.

Ardila, L. (2004), “Gasto Público y Convergencia Regional en Colombia”, Revista Ensayos Sobre Política Económica, 45: 222-268.

Aroca, P. and Bosch, M. (2000), “Crecimiento, convergencia y espacio en las regiones chilenas: 1960-1998”, Estudios de Economía, 27(2): 199-224.

Barca, F. (2009), An Agenda for A Reformed Cohesion Policy: A Place-Based Approach to Meeting European Union Challenges and Expectations, Independent Report Prepared at the Request of the European Commissioner for Regional Policy, Danuta Hübner, European Commission, Brussels

Barca, F., McCann, P. and Rodríguez-Pose, A. (2011), "The case for regional development intervention: Place-based versus place-neutral approaches", IMDEA Working Paper Series in Economics and Social Sciences, 2011/25.

Banerjee, Abhijit, and Esther Duflo. (2000), "Inequality and growth: What can the data say?” Working Paper 7793, National Bureau of Economic Research.

Barón, J. (2003), “¿Qué Sucedió con las Disparidades Económicas Regionales en Colombia entre 1980 y 2000?”, Documentos de Trabajo Sobre Economía Regional, No 38, Banco de la República, Cartagena.

Barón, J. and Meisel, A. (2003), “La Descentralización y las Disparidades Económicas Regionales en Colombia en la Década de 1990", Documentos de Trabajo Sobre Economía Regional, No 36, Banco de la República, Cartagena. 
Barro, R. (1991), “Economic Growth in a Cross-Section of Countries,'” Quarterly Journal of Economics, 106: 407-443.

Barro R. (2000), "Inequality and Growth in a Panel of Countries". Journal Economic Growth 5:5-32.

Barro, R. and Sala-i-Martin, X. (1991), "Convergence across states and regions", Brookings Papers on Economic Activity, 1:107-158.

Barro, R.J. and Sala-i-Martin, X. (1992), “Convergence”, Journal of Political Economy, 100 (2): 223-251

Barro, R. and Sala-i-Martin, X. (1997), “Technological Diffusion, Convergence, and Growth", Journal of Economic Growth, 2(1): 1-26.

Baumol, W. J. (1986), "Productivity Growth, Convergence, and Welfare - What The Long-Run Data Show”, American Economic Review, 76: 1072-1085

Becker, G. S., Philipson, T. J., Soares, R. R. (2005), “The quantity and quality of life and the evolution of world inequality", American Economic Review, 95: 277-291

Bernat, G. A. (1996), "Does manufacturing matter? A spatial econometric view of Kaldor's laws", Journal of Regional Science, 36: 463-477

Birchenall, J. and Murcia, G. (1997), “Convergencia Regional: Una Revisión del caso Colombiano", Desarrollo y Sociedad, 40: 273-308.

Bivand, R., Brunstad, R. (2005), "Regional growth in Western Europe: detecting spatial misspecification using the R environment", 45th Congress of the European-RegionalScience-Association. Amsterdam, Netherlands

Bonet, J. and Meisel, A. (1999), "La Convergencia Regional en Colombia: Una Visión de Largo Plazo, 1926-1995”, Coyuntura Económica, 1(29): 69-106. 
Bonet, J. and Meisel, A. (2006), “Polarización del Ingreso per cápita Departamental en Colombia, 1975 - 2000”, Documentos de Trabajo Sobre Economía Regional, No 76, Banco de la República, Cartagena.

Bonet, J. and Meisel, A. (2008), "Regional Economic Disparities in Colombia", Investigaciones Regionales, 14: 61-80.

Bourguignon, F., Morrisson, C. (2002), “Inequality among world citizens: 1820-1992”, American Economic Review, 92: 727-744

Branisa, B. and Cardozo, A. (2009), "Revisiting the regional growth convergence debate in Colombia using income indicators", Discussion Papers, No 194, IAI, University of Goettingen. (a)

Branisa, B. and Cardozo, A. (2009), "Regional growth convergence in Colombia using social indicators", Discussion Papers, No 195, IAI, University of Goettingen. (b)

Corporación Andina de Fomento (2010), Desarrollo Local: Hacia un Nuevo Protagonismo de las Ciudades y Regiones. Caracas: Corporación Andina de Fomento.

Cárdenas, M. (1993), “Crecimiento y Convergencia en Colombia: 1950-1990”, Planeación y Desarrollo, Edición especial DNP 35 años.

Cárdenas, M. and Pontón, A. (1995), "Growth and convergence in Colombia”, Journal of Development Economics, 47: 5-37.

Cárdenas, M., Pontón, A. and Trujillo, J. (1993), “Convergencia y Migraciones Interdepartamentales en Colombia: 1959-1989”, Coyuntura Económica, 23(1): 111-137.

Chay, K.Y. and Greenstone, M. (2000), "The Convergence in Black-White Infant Mortality Rates during the 1960s," American Economic Review, 90(2): 326-332.

Crafts, N. (2000), "Globalization and growth in the twentieth century". IMF Working Paper WP/00/44.Washington, DC: IMF. 
Dorius, S. F. (2008), “Global demographic convergence? A reconsideration of changing intercountry inequality in fertility", Population and Development Review, 34: 519-537

Dowrick, S., Dunlop, Y. and Quiggin, J. (2003), "Social Indicators and Comparisons of Living Standards", Journal of Development Economics, 70: 501-529.

Easterly, W. (1999), "Life during growth", Journal of Economic Growth, 4(3): 239276.

Elhorst J. P. (2001), "Dynamic Models in Space and Time", Geographical Analysis, 33(2): 119-140.

Elhorst, J.P. (2003), "Specification and Estimation of Spatial Panel Data Models", International Regional Science Review, 26(3): 244-268. (a)

Elhorst, J.P. (2003), “The Mystery of Regional Unemployment Differentials: Theoretical and Empirical Explanations," Journal of Economic Surveys, 17(5): 709-740. (b)

Elhorst, J.P. (2005) "Models for Dynamic Panels in Space and Time - An Application to Regional Unemployment in the EU”. Paper presented at Workshop on Spatial Econometrics, Kiel Institute for World Economics, Kiel, April 8-9, 2005.

Fingleton, B., Lopez-Bazo, E. (2006), "Empirical growth models with spatial effects", Papers in Regional Science, 85: 177-198

Franco, L. and Raymond, J. (2009), “Convergencia Económica Regional: El Caso de los Departamentos Colombianos", Ecos de Economía, 28:167-197.

Galvis, L. (2001), "La Topografía Económica de Colombia", Documentos de Trabajo Sobre Economía Regional, No 22, Banco de la República, Cartagena. 
Galvis, L. and Meisel, A. (2000), "El Crecimiento de las Ciudades Colombianas y sus Determinantes, 1973-1998”, Documentos de Trabajo Sobre Economía Regional, No 18, Banco de la República, Cartagena.

Gamarra, J. (2006), ¿Cómo se Comportan las Tasas de Desempleo en Siete Ciudades Colombianas?, Revista de Economía del Rosario, 9(2): 239-269.

Garcilazo, E., J. Oliveira Martins and W. Tompson (2010), “Why Policies May Need to be Place-Based in Order to be People-Centred," Paris: OECD Regional Development Policy Division. Available at the website: http://www.voxeu.org/

Gaviria, M. and Ballesteros, C (2010), "La convergencia de las tasas de desempleo en las regions colombianas, 2001 - 2010”, Gestión y Región, 10: 79-104

Getis, A. (1995), Spatial Filtering in a Regression Framework: Experiments on Regional Inequality, Government Expenditures, and Urban Crime. In New Directions in Spatial Econometrics, edited by L. Anselin and R. J. G. M. Florax (Berlin: Springer), pp.172-185.

Getis, A. and Ord, J. K. (1992), "The Analysis of Spatial Association by the Use of Distance Statistics", Geographical Analysis, 24(3), 189-206.

Giannias, D., Liargovas, P., Manolas, G. (1999), "Quality of life indices for analysing convergence in the European Union”, Regional Studies, 33: 27-35

Goesling, B., Firebaugh, G. (2004), "The trend in international health inequality", Population and Development Review, 30: 131-146

Gómez, C. (2006), “Convergencia Regional en Colombia: Un Enfoque en los Agregados Monetarios y en el Sector Exportador", Ensayos Sobre Economía Regional, No 45, Banco de la Republica, Cali. 
Islam, N. (1995), “Growth Empirics: A Panel Data Approach”, Quarterly Journal of Economics, 110: 1127-1170.

Hobijn, B., Franses, P.H. (2001), “Are Living Standards Converging?” Structural Change and Economic Dynamics, 12: 171-200.

Hsiao, C. and Sun B. (2000), “To Pool or Not to Pool Panel Data,' in J. Krishnakumar and E. Ronchetti (eds.), Panel Data Econometrics: Future Directions: Papers in Honour of Professor Pietro Balestra. Amsterdam: Elsevier, pp. 181-198.

Izenman, A. J. and Sommer, C. (1988), "Philatelic Mixtures and Multimodal Densities", Journal of the American Statistical Association, 83 (404): 941-953.

Kenny, C. (2005), "Why Are We Worried About Income? Nearly Everything that Matters is Converging", World Development, 33(1), 1-19.

Liargovas, P. G. and Fotopoulos, G. (2009), "Socioeconomic indicators for analyzing convergence: The case of Greece: 1960-2004", Social Indicators Research, 93: 315330.

Lopez-Bazo, E., Vaya, E., Mora, A. J., Surinach, J. (1999), "Regional economic dynamics and convergence in the European Union", Annals of Regional Science, 33: 343-370.

Magrini, S. (2007), "Analysing Convergence through the Distribution Dynamics Approach: Why and How?", Working Paper Department of Economics Ca'Foscari, University of Venice. No. 13 /WP/2007.

Mairesse, Jacques. (1990), “Time-Series and Cross-Sectional Estimates on Panel Data: Why are They Different and Why They Should be Equal,', in J. Hartog, G. Ridder, and J. Theeuwes (eds.), Panel Data and Labor Market Studies. New York: North Holland, pp. 81-95. 
Mankiw, N. G., Romer, D., Weil, D. N. (1992), “A Contribution to the Empirics of Economic-Growth", Quarterly Journal of Economics, 107: 407-437.

Marchante, A. J. and Ortega, B. (2006), "Quality of life and economic convergence across Spanish regions, 1980-2001”, Regional Studies, 40: 471-483.

Martínez, A. (2006), “Determinantes del PIB per cápita de los Departamentos Colombianos 1975-2003”, Archivos de Economía, No 318, DNP, Bogotá.

Meisel, A. (1993), "Polarización o Convergencia? A propósito de Cárdenas, Pontón y Trujillo”. Coyuntura Económica, 23(2): 153-161.

Meisel, A. (2007), "Por qué se Necesita una Política Económica Regional en Colombia", Documentos de Trabajo Sobre Economía Regional, No 100, Banco de la República, Cartagena.

Meisel, A. and Vega, M. (2007), "The Biological Standard of Living (and its Convergence) in Colombia, 1870-2003”, Economics and Human Biology, 5: 100-122.

Micklewright, J. and Stewart, K. (1999), "Is the well-being of children converging in the European Union?”, Economic Journal, 109(459): F692-F714.

Minnesota Population Center (2010), Integrated Public Use Microdata Series, International: Version 6.0 [Machine-readable database]. Minneapolis: University of Minnesota.

Neumayer, E. (2003), “Beyond Income: Convergence in Living Standards, Big Time”, Structural Change and Economic Dynamics, 14: $275-796$

OECD (2009), How Regions Grow, Paris: Organisation for Economic Growth and Development. (a)

OECD (2009), Regions Matter: Economic Recovery, Innovation and Sustainable Growth, Paris: Organisation for Economic Growth and Development. (b) 
Partridge, M. (2005), "Does income distribution affect U.S. state economic growth?" Journal of Regional Science, 45(2): 363-394

Quah, D. T. (1996), "Empirics for Economic Growth and Convergence", European Economic Review, 40: 1353-1375

Quah, D.T. (1993), "Empirical Cross-section Dynamics in Economic Growth", European Economic Review, 37(2-3): 426-434. (a)

Quah, D.T. (1993), “Galton's Fallacy and Tests of the Convergence Hypothesis", Scandinavian Journal of Economics, 95(4): 427-443. (b)

Quah, D.T. (1996), “Convergence Empirics Across Economies with (Some) Capital Mobility", Journal of Economic Growth, 1(1): 95-124. (a)

Quah, D.T. (1996), "Empirics for Economic Growth and Convergence", European Economic Review, 40 (6): 1353-1375. (b)

Quah, D.T. (1996), "Ideas Determining Convergence Clubs". LSE Economics Department Working Paper, London: London School of Economics. (c)

Quah, D.T. (1997), "Empirics for Growth and Distribution: Stratification, Polarization, and Convergence Clubs", Journal of Economic Growth, 2 (1): 27-59.

Partridge, Mark D. (2005), "Does income distribution affect U.S. state economic growth?", Journal of Regional Science, 45(2): 363-394.

Ram, R. (1992), "Intercountry inequalities in income and basic needs indicators: a recent perspective" World Development, 20(6): 899-905.

Rey, S. and Janikas, M (2005), "Regional convergence, inequality, and space", Journal of Economic Geography, 5(2):155-176. 
Rey, S. J. and Montouri, B. D. (1999), “US Regional Income Convergence: a Spatial Econometric Perspective”. Regional Studies, 33: 143-156

Rocha, R. and Vivas, A. (1998), “Crecimiento Regional en Colombia: ¿Persiste la Desigualdad?", Revista de Economía del Rosario, 1:67-108.

Royuela, V., Artis, M. (2006), "Convergence analysis in terms of quality of life in the urban systems of the Barcelona province, 1991-2000”, Regional Studies, 40: 485-492

Sala-i-Martin, X. (1996), "Regional Cohesion: Evidence and Theories of Regional Growth and Convergence", European Economic Review, 40(6): 1325-1352.

Salgado-Ugarte, I.H., Shimizu, M. and Taniuchi, T. (1997), "Nonparametric Assessment of Multimodality for Univariate Data”, Stata Technical Bulletin, 38: 27-35. Sanchez, J. and Nuñez, J. (2000), “Geography and Economic Development: A Municipal Approach for Colombia", Archivos de Macroeconomía, No 135, DNP, Bogotá.

Sen, A. (1973), On economic inequality. Oxford: Clarendon Press.

Sen, A. (1987), The Standard of Living (University Press, Cambridge).

Sen, A. (1993), "Capability and well being”, in M.C. Nussbaum and A. Sen (eds.), The Quality of Life, Wider Studies in Development Economies (Clarendon Press, Oxford).

Sen, A. (1997), On Economic Inequality. Expanded edition with substantial annexe by J. Foster and A. Sen (Clarendon Press, Oxford).

Sheather, S. J. and Jones, M. C. (1991), “A Reliable Data-based Bandwidth Selection Method for Kernel Kensity Estimation, Journal of the Royal Statistical Society, Series B, 53: 683-690. 
Silverman, B. W. (1981), "Using Kernel Density Estimates to Investigate Multimodality", Journal of the Royal Statistical Society, Series B, 43 (1): 97-99.

Silverman, B. W. (1983), "Some Properties of a Test for Multimodality Based on Kernel Density Estimates. In Probability, Statistics and Analysis, ed. J. F. C. Kingman and G. E. H. Reuter, 248-249. Cambridge: Cambridge University Press.

World Bank. (2009), World Development Report 2009: Reshaping Economic Geography. Washington, DC: World Bank. 
Figure 1. Colombia and its departments

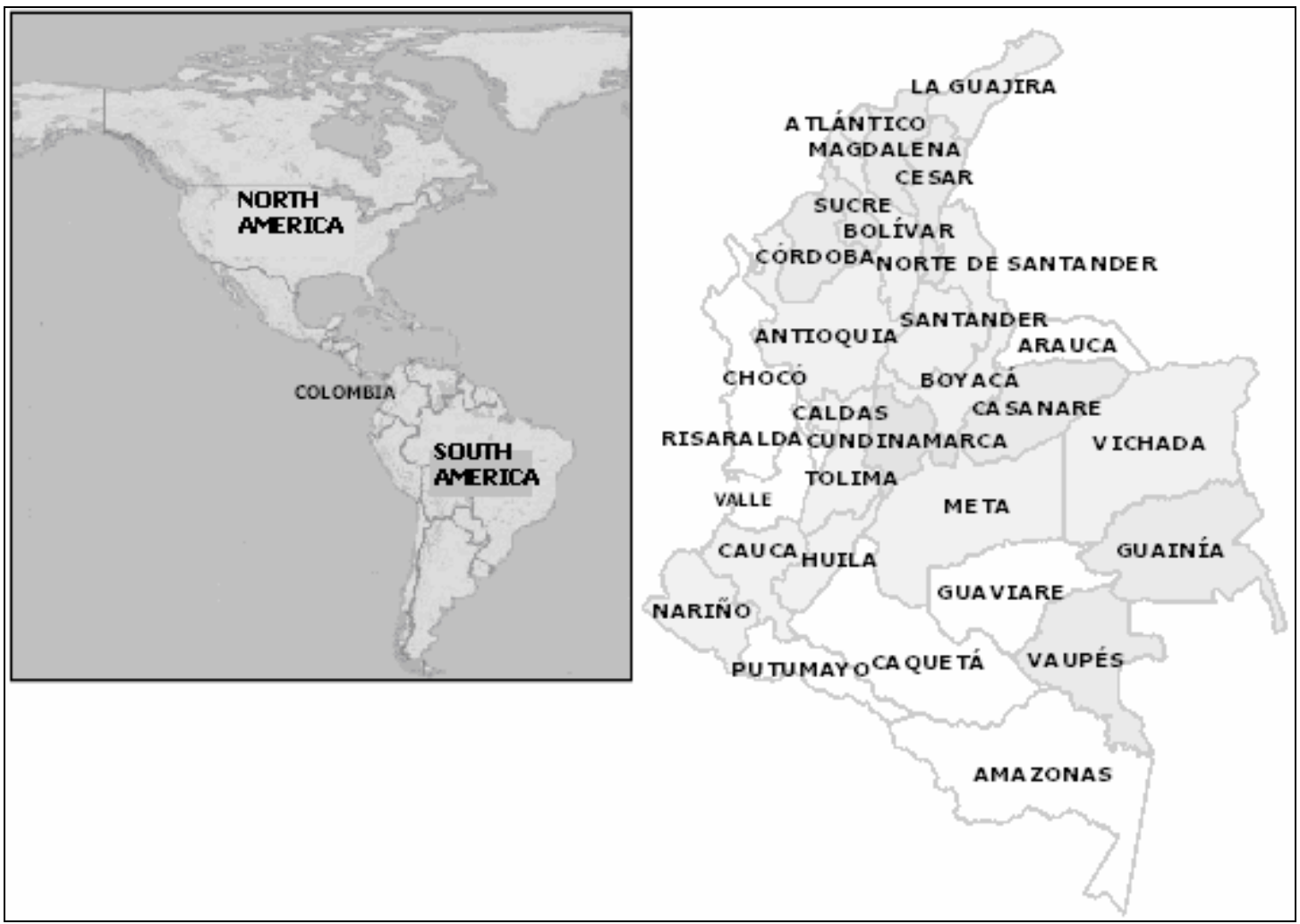

Source: Instituto Geográfico Agustín Codazzi - IGAC 
Table 1. Economic and social indicators in Colombia and other nearby countries

\begin{tabular}{|l|c|c|c|c|c|c|}
\hline & Colombia & Brazil & Chile & Argentina & Mexico & United States \\
\hline $\begin{array}{l}\text { Per capita GNI (constant } \\
2005 \text { international US\$) }\end{array}$ & 8,315 & 10,162 & 13,329 & 14.527 & 13,245 & 43,017 \\
\hline $\begin{array}{l}\text { Annual growth rate of GDP } \\
\begin{array}{l}\text { 1990-2009 (at constant } \\
\text { prices) }\end{array}\end{array}$ & $3.4 \%^{*}$ & $2.7 \%$ & $5.1 \%^{*}$ & $3.8 \%$ & $2.3 \%$ & $2.4 \%$ \\
\hline Gini coefficient ${ }^{\text {a }}$ & 58.5 & 53.9 & 22.6 & 45.8 & 51.7 & 40.8 \\
\hline $\begin{array}{l}\text { MPI: Population living below } \\
\$ 1.25 \text { PPP per day (\%) }\end{array}$ & $16 \%$ & $3.8 \%$ & $0.8 \%$ & $0.9 \%$ & $3.4 \%$ & - \\
\hline $\begin{array}{l}\text { Adult illiteracy rate, both } \\
\text { sexes (\% aged 15 and above) } \\
\text { a }\end{array}$ & $6.8 \%$ & $10 \%$ & $1.4 \%$ & $2.3 \%$ & $6.6 \%$ & - \\
\hline Life expectancy at birth $^{\text {a }}$ & 73.7 & 73.5 & 79.1 & 75.9 & 77 & 78.5 \\
\hline $\begin{array}{l}\text { Intentional homicide rate per } \\
100,000 \text { population }(2010)^{c}\end{array}$ & 33.4 & 22.7 & 3.7 & 5.5 & 18.1 & 5 \\
\hline
\end{tabular}

Sources: a) United Nations Developed Program (2011 HDI report); b) International Financial Statistics; c) United Nations Office on Drugs and Crime - 2010. * represents GDP growth between 1990-2008. 
Table 2. Sigma convergence (coefficient of variation) and Moran's I statistic

\begin{tabular}{|c|c|c|c|c|c|c|c|c|c|c|c|c|}
\hline & \multicolumn{2}{|c|}{$\begin{array}{l}\text { Real GDP per } \\
\text { capita }\end{array}$} & \multicolumn{2}{|c|}{$\begin{array}{c}\text { Real income per } \\
\text { capita ( } 24 \\
\text { departments) } \\
\end{array}$} & \multicolumn{2}{|c|}{ Literacy rate } & \multicolumn{2}{|c|}{$\begin{array}{c}\text { Life expectancy } \\
\text { at birth }\end{array}$} & \multicolumn{2}{|c|}{$\begin{array}{l}\text { Infant survival } \\
\text { rate }\end{array}$} & \multicolumn{2}{|c|}{ Non-murder rate } \\
\hline & $\mathrm{CV}$ & Moran's I & $\mathrm{CV}$ & Moran's I & $\mathrm{CV}$ & Moran's I & $\mathrm{CV}$ & Moran's I & $\mathrm{CV}$ & Moran's I & $\mathrm{CV}$ & Moran's I \\
\hline 1975 & 0.4638 & 1.253 & \begin{tabular}{|l|}
0.4611 \\
\end{tabular} & 0.718 & 0.108 & 0.776 & & & & & & \\
\hline 1980 & 0.4423 & 1.222 & \begin{tabular}{|l|}
0.4623 \\
\end{tabular} & 0.505 & & & & & & & & \\
\hline 1985 & 0.4523 & 1.152 & 0.4711 & 0.424 & 0.074 & $1.455^{*}$ & 0.058 & $4.143^{* * * *}$ & 0.0151 & $2.065^{* *}$ & & \\
\hline 1990 & 0.5807 & $1.815 * *$ & \begin{tabular}{|l|}
0.4087 \\
\end{tabular} & 0.690 & & & 0.052 & $3.830^{* * *}$ & 0.0155 & $1.448^{*}$ & 0.000404 & 0.359 \\
\hline 1995 & 0.5238 & $1.965 * *$ & \begin{tabular}{|l|}
0.3817 \\
\end{tabular} & 0.545 & 0.059 & 1.202 & 0.043 & $3.709 * * *$ & 0.0151 & 1.180 & 0.000355 & -0.702 \\
\hline 2000 & 0.6351 & 1.045 & \begin{tabular}{|l|}
0.3308 \\
\end{tabular} & 0.899 & 0.064 & $2.381 * * *$ & 0.035 & $3.397 * * *$ & \begin{tabular}{|l|}
0.0146 \\
\end{tabular} & 1.105 & 0.000325 & -0.439 \\
\hline 2005 & 0.5000 & $1.326 *$ & & & & & & & & & 0.000256 & 0.625 \\
\hline
\end{tabular}


Table 3. Beta convergence. Cross-section estimates

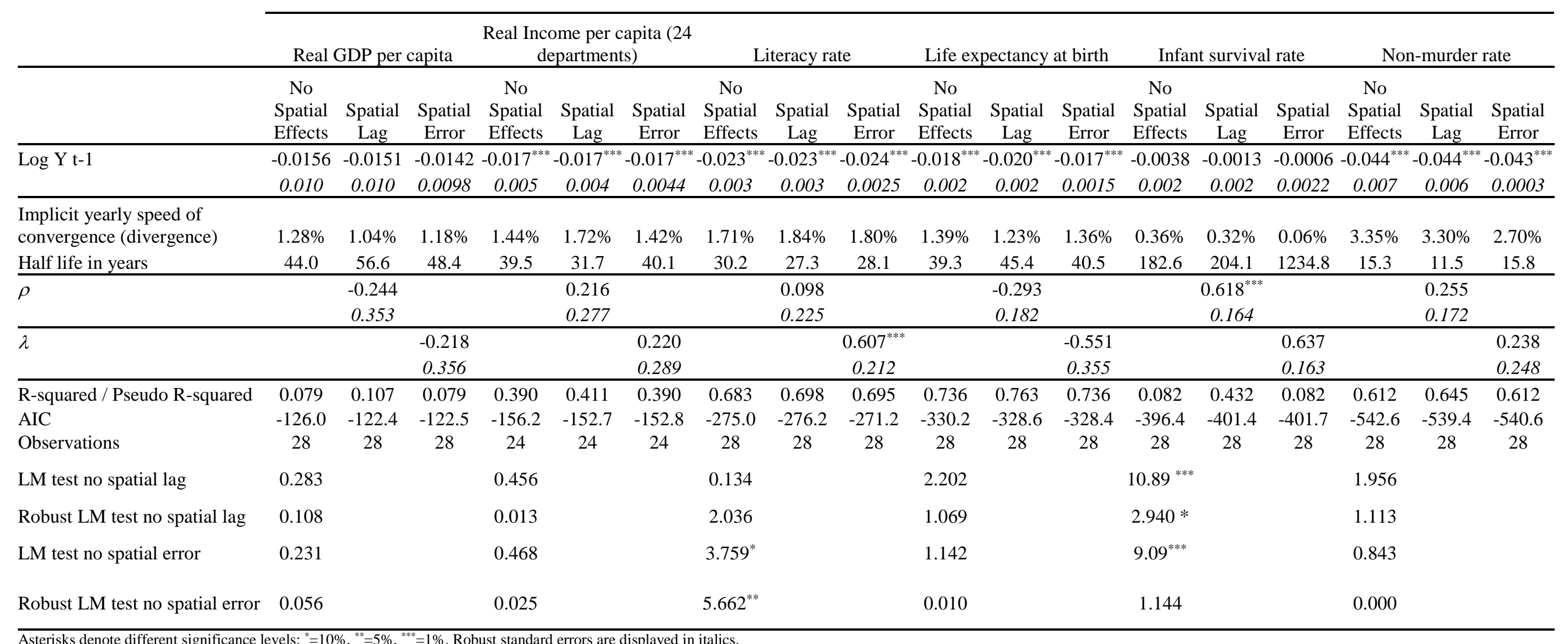

Asterisks denote different significance levels: ${ }^{*}=10 \%,{ }^{* *}=5 \%,{ }^{* * *}=1 \%$. Robust standard errors are displayed in italics.

For several models we computed a pseudo R-Squared as the correlation between the original and fitted values of the endogenous variable. 
Table 4. Beta convergence. Panel data estimates with cross-section and time series fixed effects

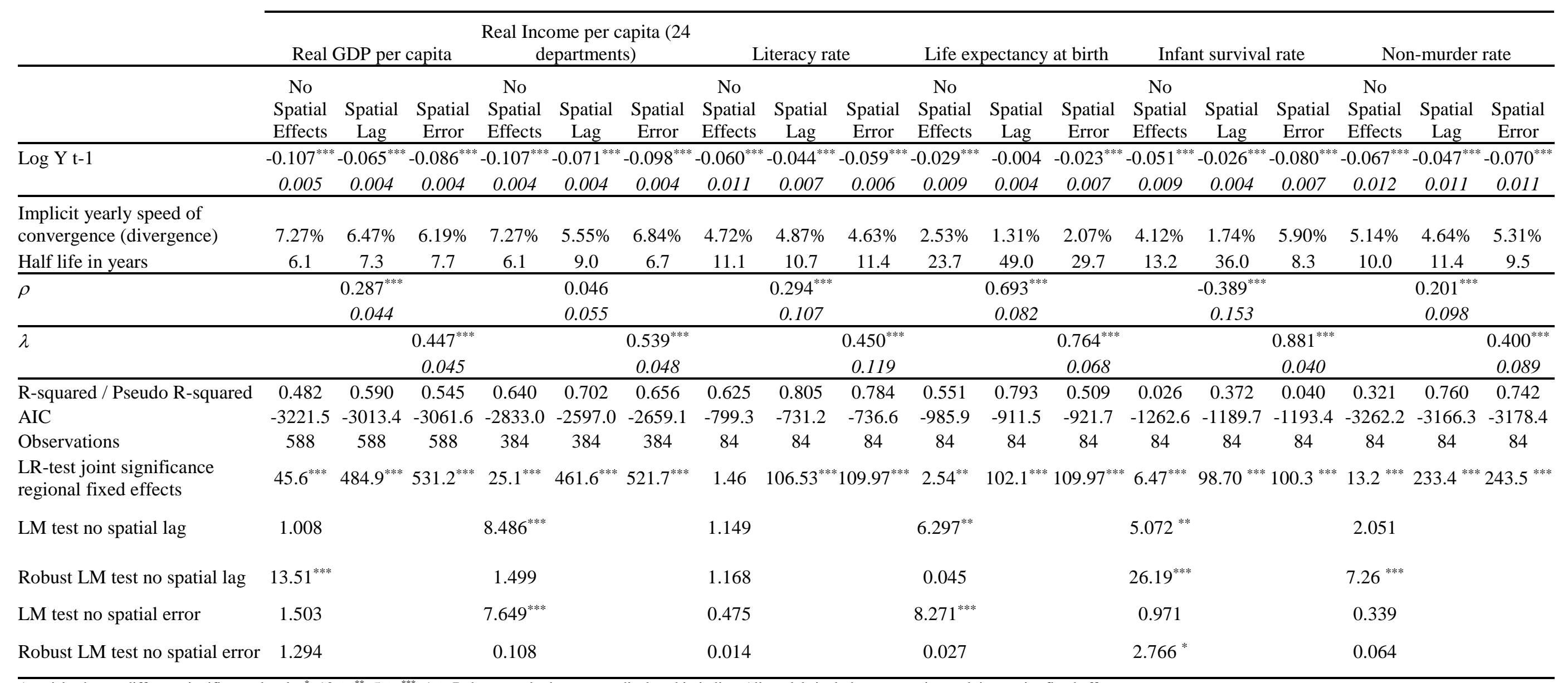

Asterisks denote different significance levels: ${ }^{*}=10 \%,{ }^{* *}=5 \%,{ }^{* * *}=1 \%$. Robust standard errors are displayed in italics. All models include cross section and time series fixed effects.

For several models we computed a pseudo R-Squared as the correlation between the original and fitted values of the endogenous variable. 
Figure 2. Distribution of the variables at department level
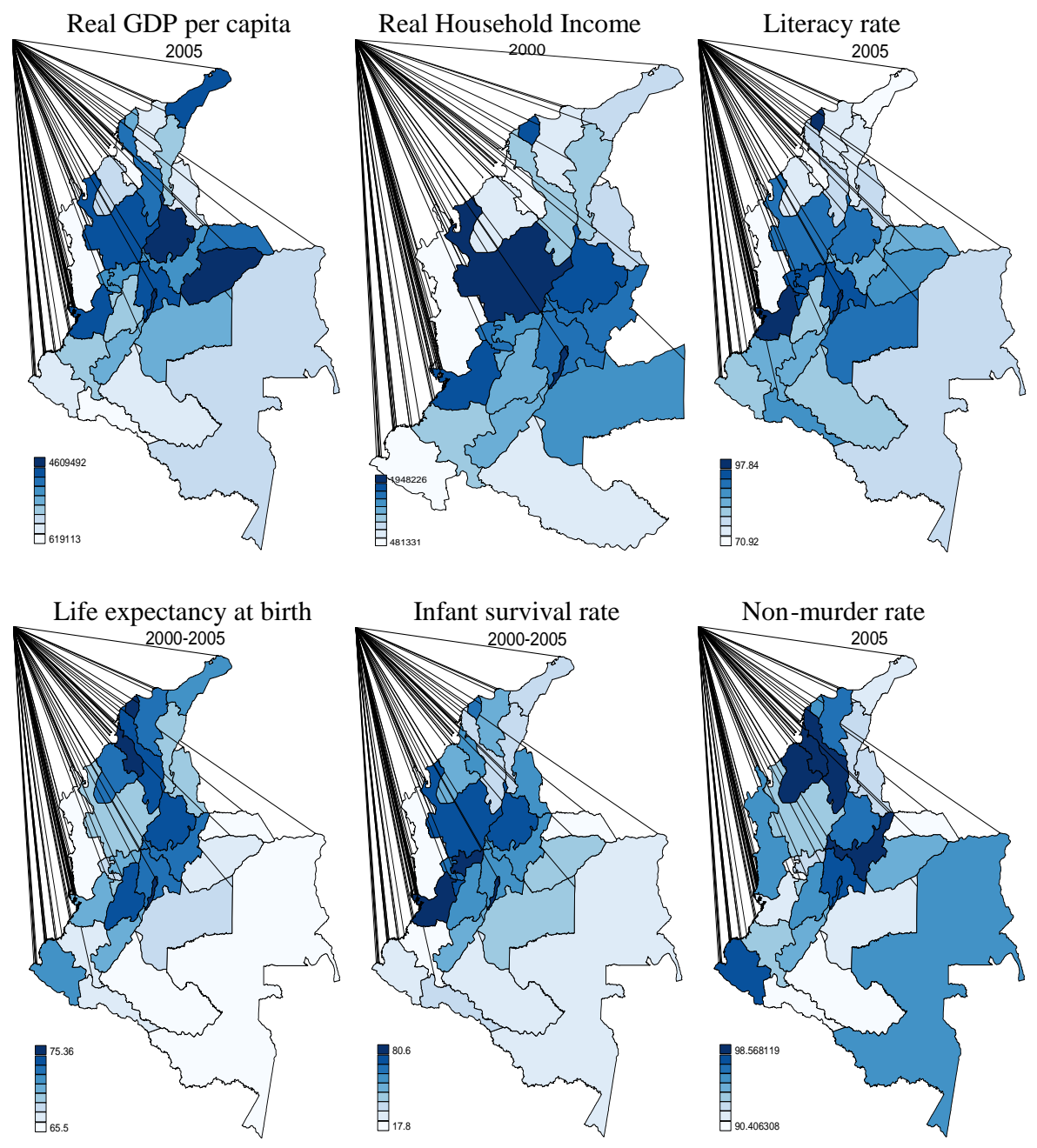


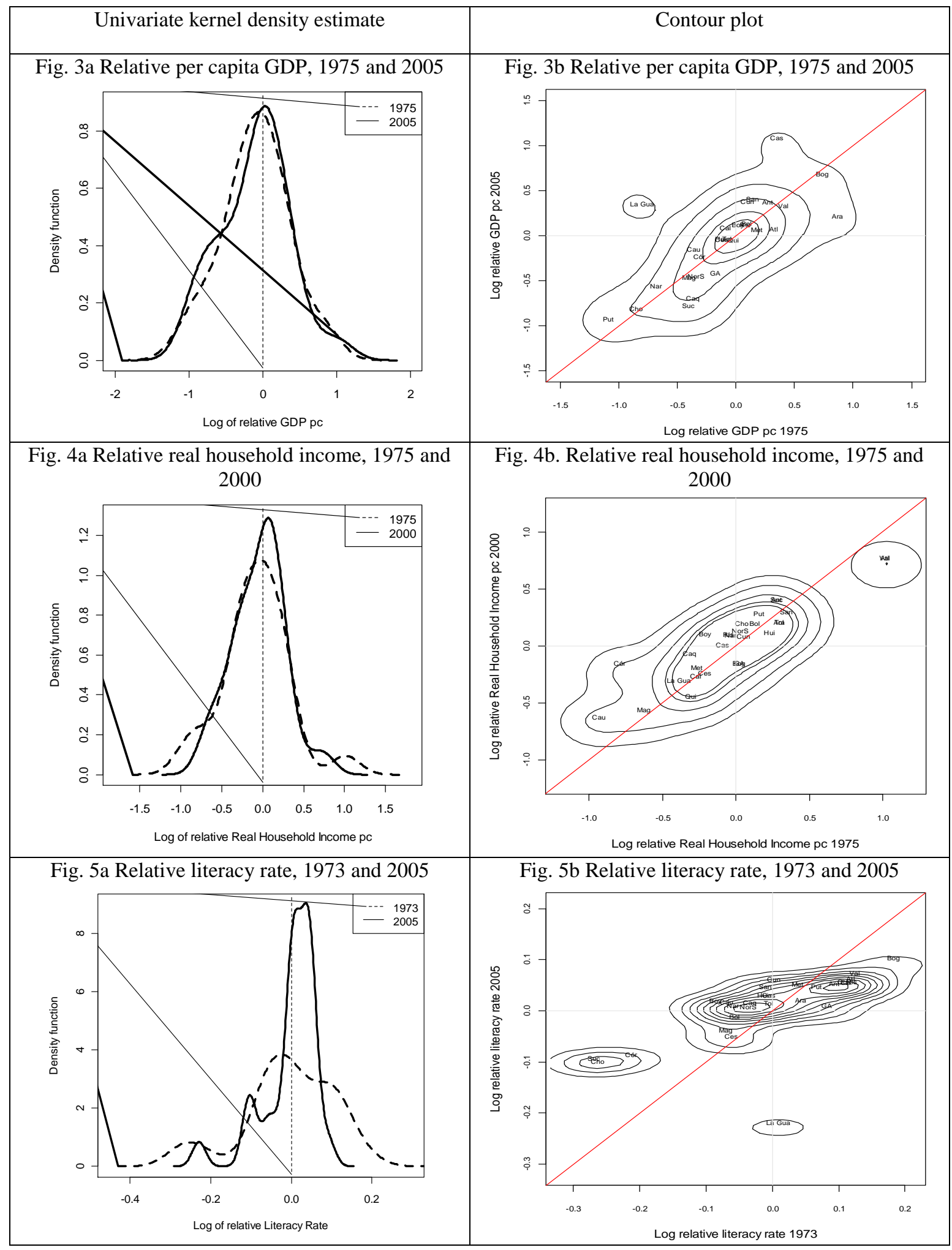




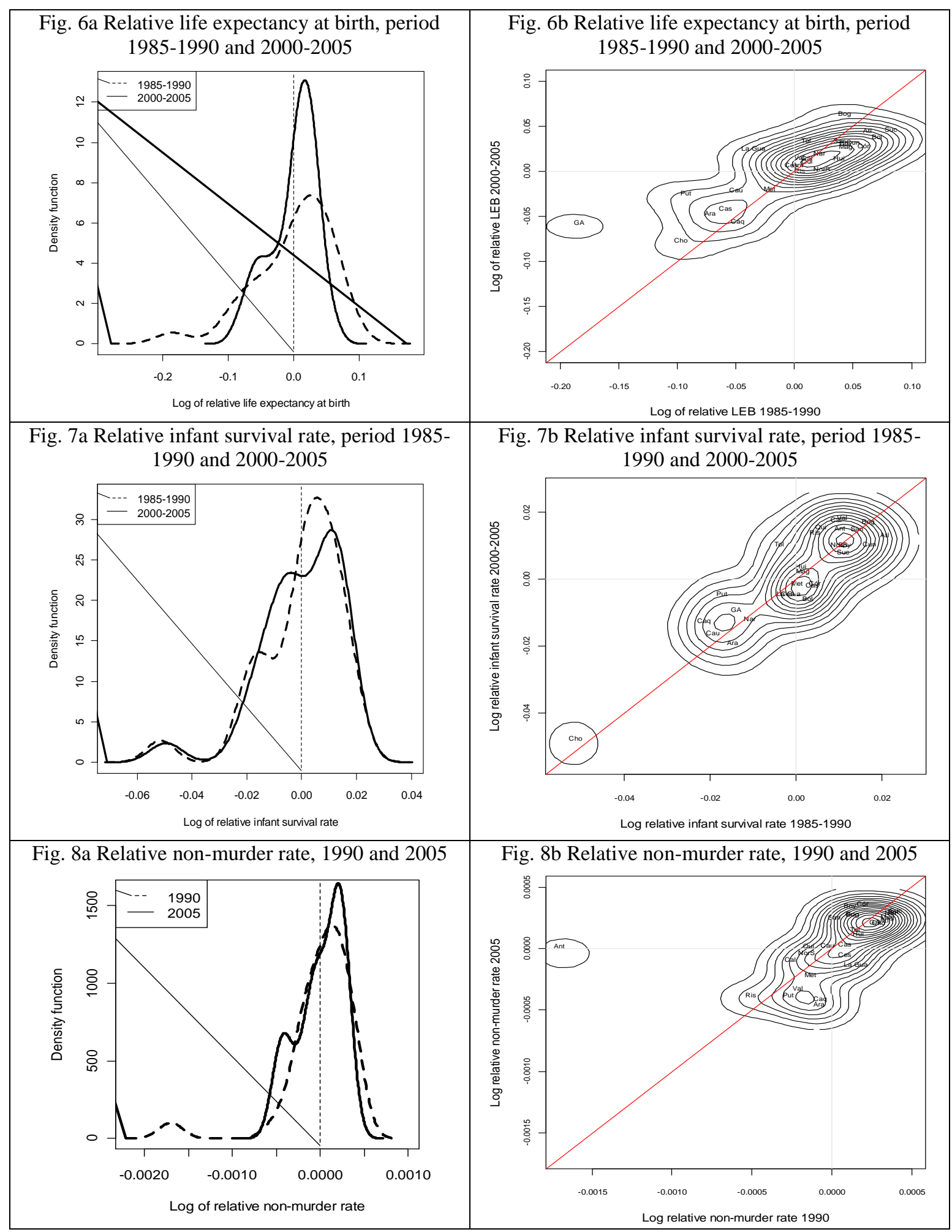

